Case report

https://www.journal-imab-bg.org

Case report

\title{
THYROID METASTASIS OF A SQUAMOUS CELL CARCINOMA OF THE TONGUE - A RARE CASE REPORT
}

\author{
Gergana Tosheva ${ }^{1}$, Mira Siderova ${ }^{1}$, Elitsa Encheva ${ }^{2}$, Doroteya Malinova ${ }^{3}$ \\ 1) Endocrinology Department, Faculty of Medicine, Clinic of Endocrinology and \\ Metabolic Diseases, University Hospital St. Marina, Medical University - Varna, \\ Bulgaria \\ 2) Radiotherapy Department, Faculty of Medicine, Clinic of Diagnostics Imaging \\ and Radiotherapy, University Hospital St. Marina, Medical University - Varna, \\ Bulgaria \\ 3) Department of General and Clinical Pathology, Faculty of Medicine, Clinic \\ of General and Clinical Pathology, Forensic Medicine and Deontology, \\ University Hospital St. Marina, Medical University - Varna, Bulgaria.
}

\begin{abstract}
Introduction: We present a patient with carcinoma of the tongue with à lymph node and thyroid metastases. The squamous cell cancer of the tongue's 5-year survival rate has not been improved in the last three decades. Most common sites of metastases are the locoregional lymph nodes, followed by distant pulmonary, liver, bone and skin metastasås. Only ten cases of metastases to the thyroid gland are reported in the literature.

Case report: A 79-year old man presented to the University Hospital in Varna, Bulgaria. Two months before admission, he noticed swelling of the tongue and progressive weight loss. The inspection of the oral cavity revealed a lesion on the left margin of the tongue. A biopsy was performed with a histological result of differentiated squamous cell carcinoma of the tongue. A computed tomography scan of the head and neck region discovered a lesion in the right thyroid lobe. 18-fluoro-2-deoxy-glucose-positron emission tomography imaging showed a metabolically active tumor of the tongue with hypermetabolic metastatic cervical lymph nodes and a zone with abnormally elevated fixation of $18 \mathrm{~F}-\mathrm{FDG}$ in the central part of the soft palate. The described thyroid nodule did not have an increased tracer uptake. It was cytologically assessed after fine-needle aspiration biopsy (FNAB) as a metastasis from squamous cell carcinoma of the tongue.
\end{abstract}

Conclusions: Distant metastases from tongue cancer to the thyroid gland are extremely rare and mostly occur in the advanced stages of malignancy.

Keywords: tongue, matastasis, thyroid gland,

\section{INTRODUCTION}

Oral squamous cell carcinoma (OSCC) is the sixth most common cancer in the world [1]. A spread of 10-20 per 100000 people is calculated by European statistics [2]. Between $25 \%$ and $40 \%$ of all cases of the oral cavity, tumors are diagnosed as squamous cell carcinoma of the tongue (SCCT) [3].

Risk factors for head and neck squamous cell carcinoma (HNSCC) carcinogenesis are tobacco, alcohol, the human papilloma virus (HPV), Epstein-Barr virus (EBV), herpes simplex virus (HSV), immunosuppression, polymorphism of interleukin 6 (IL6), tumor necrosis factor (TNF) [4] and inherited syndromes, e.g. Fanconi anemia, aplastic anemia [5].

The poor 5-year survival of the HNSCC has not been improved in the past three decades despite medical therapy advances. SCCT such as the other HNSCC most often metastasize by the lymphatic route. Osaki et al. reported an incidence of hematogenous distant metastasis of $4.1 \%$ [6]. The most common sites are the lungs (65\%), bones (25\%), liver (24\%) and skin (14\%) [7].

Fewer than 450 cases of metastasis to the thyroid gland of all kind of origin are reported in the literature with only ten from HNSCC. We found just two case reports of squamous cell carcinoma of the tongue- the first is described by the oncology team of Thomas and coauthors [8] and the second- from Tsuyoshi and coauthors [9]. Others report an average survival of 30 months for patients who underwent thyroid resection because of metastases there and even worse for those who were not operated 12 months [10].

\section{CASE REPORT}

A 79-year old man presented to The University Hospital "St. Marina" in Varna, Bulgaria. An information leaflet was offered and a written informed consent was ob- 
tained from the patient. Two months before admission, he noticed swelling in the tongue, followed by difficulty swallowing of liquid-paste foods and progressive weight reduction.

His medical history showed arterial hypertension, aortic stenosis, Parkinson's disease and a stroke two years ago with concomitant medications for these conditions and no past history of smoking.

On clinical examination, he was in a poor general condition with height $175 \mathrm{~cm}$, weight $73 \mathrm{~kg}$, BMI 24 . The oral cavity inspection detected a poorly demarcated lesion on the left margin of the tongue with ulceroproliferative areas and a size of $4.0 \times 2.1 \times 1.5 \mathrm{~cm}$, which is shown in Figure 1. No enlarged lymph nodes were detected. The thyroid gland was slightly enlarged on palpation mainly due to enlargement of the right lobe. Breathing sounded vesicular with single wheezes in the right pulmonary base. On heart auscultation there was a rhythmic heartbeat and pansystolic murmur all over the precordium with punctum maximum at the aortic auscultatory zone, radiating to the carotid arteries. There were not any abnormalities during an abdominal examination. Static tremor of the extremities was noticed.

Fig. 1. Photography of the poorly demarcated lesion on the left margin of the tongue

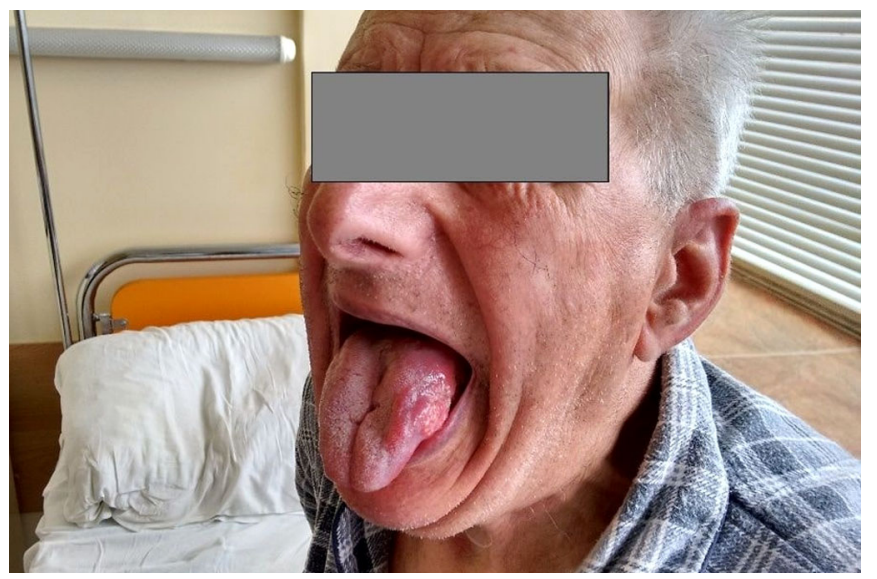

First, an excision biopsy of the tongue lesion was performed with a histological result of highly to moderately differentiated squamous cell carcinoma of the tongue. Figure 2 presents the focal superficial keratinisation with a formation of keratin pearls, and the stratified squamous epithelium of the tongue was with acanthosis and pseudoepitheliomatous hyperplasia. A computed tomography (CT) scan of the head and neck region and Xray of the chest were performed to stage the disease. The CT detected a hypodense lesion with a heterogeneous structure in the right lobe of the thyroid gland. An X-ray of the chest was performed with pneumofibrosis, basal emphysema, atherosclerosis of the aorta and suspected metastasis in the first right rib.
Fig. 2. Histology: the stratified squamous epithelium of the tongue was with acanthosis and pseudoepitheliomatous hyperplasia, focal superficial keratinisation was present. Tumor consisted of sheets of large polygonal cells containing keratin, a formation of keratin pearls was present.

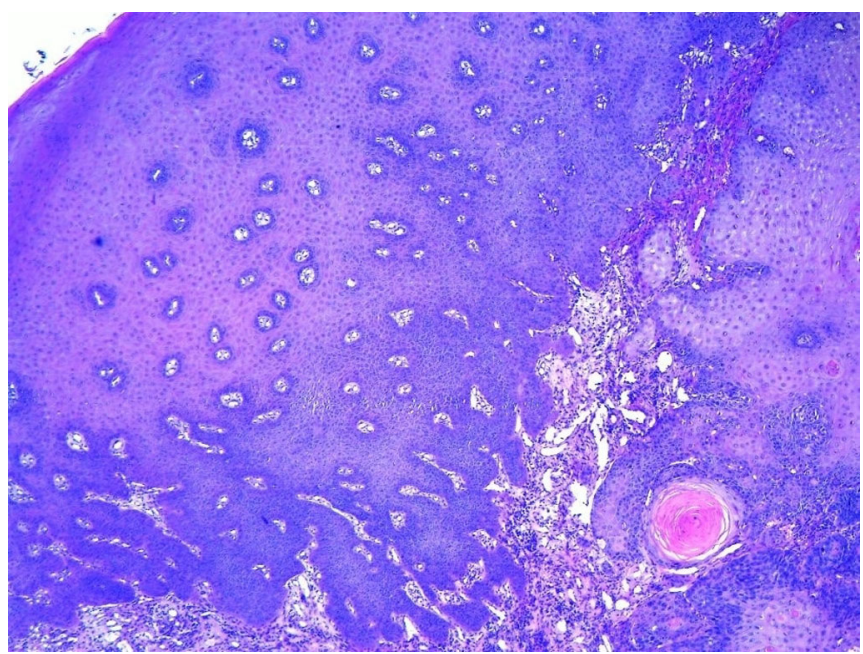

Thyroid function was assessed with FT4 and FT3 within the reference range and a slightly elevated thyroidstimulating hormone (TSH $6.23 \mathrm{IU} / \mathrm{mL}$ ). Levothyroxine treatment of subclinical hypothyroidism was not initiated because of the advanced age of the patient.

Thyroid ultrasound revealed an enlarged right thyroid lobe with a solid encapsulated hypoechoic nodule with an intranodular macrocalcificate, shown in Figure 3 (Figure 3 ). The nodule measures $22 \times 18 \times 15 \mathrm{~mm}$ in size with peripheral vascularization on Doppler US. The surrounding thyroid parenchyma was slightly inhomogeneous.

Fig. 3. Thyroid ultrasound

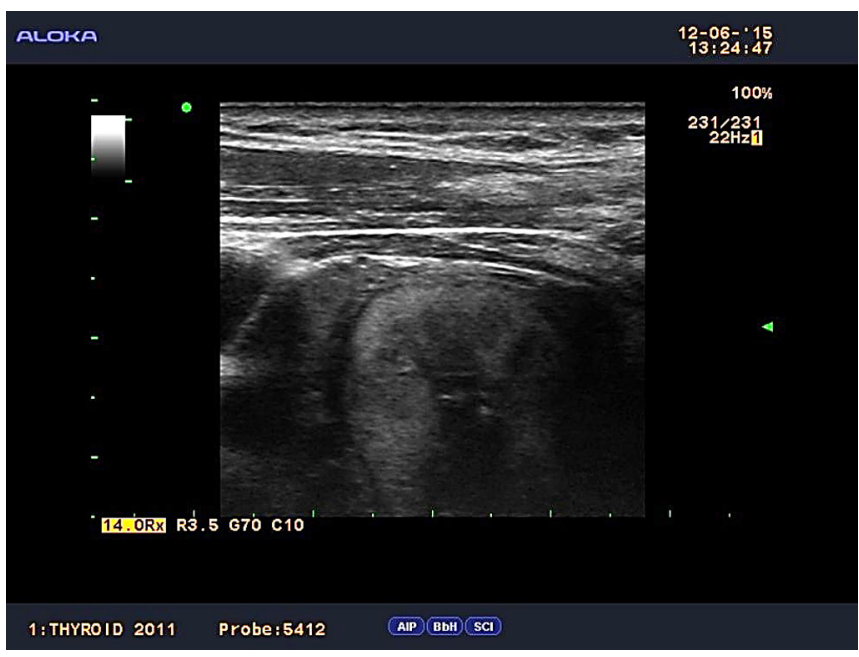

A fine-needle aspiration biopsy (FNAB) of the thyroid nodule was performed. The cytological assessment revealed blood and blood elements, fibrovascular frag- 
ments, concentrated colloid, macrophages, groups of tumor cells with squamous cell differentiation and anuclear squamous cells consistent with metastasis from squamous cell carcinoma of the tongue to the thyroid (Figure 4).

Fig. 4. The cytological result

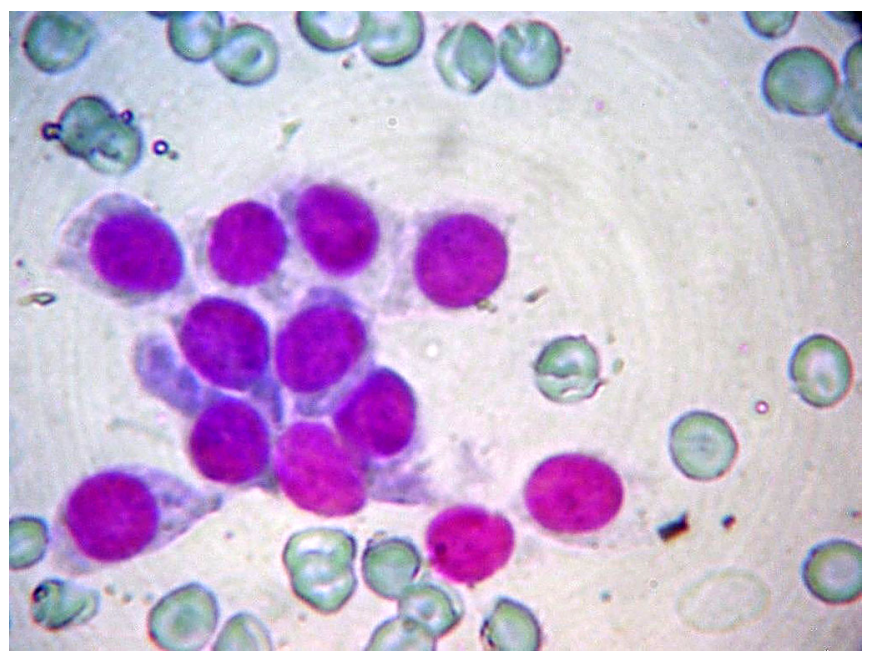

We continued with further imaging studies like an abdominal ultrasound with no abnormalities detected. Fluorine 18-fluoro-2-deoxy-glucose-positron emission tomography (18F-FDG-PET) scans showed metabolically active tumor of the tongue with hypermetabolic metastatic cervical lymph nodes and a zone with abnormally elevated fixation of $18 \mathrm{~F}-\mathrm{FDG}$ in the central part of the soft palate. The described thyroid nodule did not have increased tracer uptake.

Fig. 5. PET-CT of the whole body

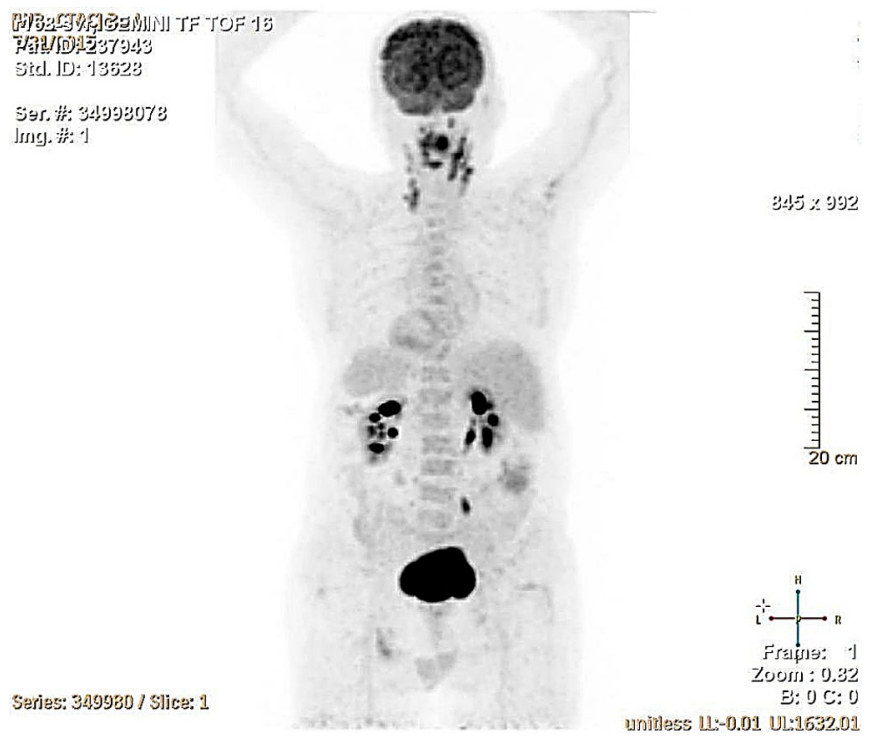

After being discussed in a multidisciplinary tumor board meeting, the patient was staged as T3N1M1. At this stage, surgical therapy was not indicated, and the patient was referred for concurrent chemoradiation (CCRT). He completed 70 Gy (divided in 35 fractions) using intensity modulated radiation therapy along with Cisplatin for days 1, 22 and 43. However, his condition deteriorated, and after 6 months, he was admitted in the intensive unit for palliative care. On clinical examination, he was somnolent, with oral cavity ulcerations, laboratory findings of bacterial inflammation. Despite the treatment with antibiotics, the patient finally deceased.

\section{DISCUSSION}

Approximately $3.6 \%$ of all cancer deaths are caused by oropharyngeal cancer [11]. The highest incidence and prevalence of this cancer is reported among some populations in the Indian subcontinent, chewing tobacco, areca nut and betel quid [12]. The epidemiology of oropharyngeal cancer has changed over the past several years with an increasing incidence among alcohol and tobacco nonusers, young women and subjects under 45 years of age. Most reports publish increasing frequency ranging from $0.4 \%$ to $3.3 \%$ per year [13].

Because of its origin, oral cancer arises exceptionally on the background of premalignant dysplasia of oral epithelium. However, de novo tumor formation is also possible. Lateral borders and the anterior two-thirds of the tongue are the most commonly affected areas.

In our patient, the primary lesion was also found in the lateral tongue border. He was staged as T3N1M1 due to the presence of metastatic cervical lymph nodes, a thyroid metastasis and possible bone metastasis in the first right rib. A locoregional spread to the soft palate could be discussed because of the abnormally elevated fixation of 18F-FDG described. Nevertheless, this would not affect the choice of treatment because of the advanced stage of the disease.

Although not so common, haematogenic metastases worsen the survival of a patient with HNCC [7]. A previous study described a rate of distant metastases in cases of tongue cancer to be $4.1 \%$ [5]. In this case, we report a patient with extremely rare haematogenic spread to the thyroid gland. To our knowledge, there are just two similar cases described.

Oral surgery (partial glossectomy) or radiotherapy are the first-line treatments of choice for early-stage tongue cancer. When the disease is advanced, wide excision and reconstructive surgery are required, where possible. Otherwise, chemoradiotherapy is one of the therapy options intending to preserve the organ in such patients. McDowell et al. found that an alternative to surgery in patients with tongue cancer staged as T4 may be chemoradiotherapy. They investigated disease progression and functional outcomes in patients with T4 SCCT and did not find a significant difference in the five-year survival rate between patients treated with surgery and those with chemoradiotherapy [14]. Stenson et al. reported that the need for total glossectomy in such patients might be avoided by systemic chemoradiotherapy [15].

A study performed by Jones et al. suggests that radiotherapy and surgery could control this disease with similar effect. There are no treatment options for SCCT that is locally advanced (T3-4) at the presentation that 
can offer better survival results over palliation [16]. In our case, the combination of radiation therapy along with Cisplatin was the treatment of choice due to the advanced age and multiple comorbidities of the patient.

Another option for the treatment of advanced tongue cancer is the superselective intra-arterial chemoradiotherapy infusion $[17,18,19,20]$. Tumor-feeding artery catheterization could improve therapeutic results.

\section{CONCLUSION}

Metastases to the thyroid gland are extremely rare, especially those originating from tongue cancer. For patients with oral SCC presented with a metastatic spread at the time of diagnosis, the prognosis is poor with short life expectancy.

\section{REFERENCES:}

1. Parkin DM, Bray F, Ferlay J, Pisani P. Global cancer statistics, 2002. CA Cancer J Clin. 2005 Mar-Apr; 55(2):74-108. [PubMed]

2. Credé A, Locher M, Bredell M. Tongue cancer in young patients: case report of a 26-year-old patient. Head Neck Oncol. 2012 May;4(1):20. [PubMed]

3. Amar A, Rapoport A, Curioni OA, Dedivitis RA, Cernea CR, Brandão LG. Prognostic value of regional metastasis in squamous cell carcinoma of the tongue and floor of mouth. Braz J Otorhinolaryngol. 2013 Nov-Dec; 79(6):734-7. [PubMed]

4. Dhull AK, Atri R, Dhankhar R, Chauhan AK, Kaushal V. Major Risk Factors in Head and Neck Cancer: A Retrospective Analysis of 12-Year Experiences. World J Oncol. 2018 Jun;9(3):80-84. [PubMed]

5. Báez A. Genetic and environmental factors in head and neck cancer genesis. J Environ Sci Health C Environ Carcinog Ecotoxicol Rev. 2008 AprJun;26(2):174-200. [PubMed]

6. Osaki T, Yoneda K, Yamamoto T, Kimura T, Matuoka H, Sakai H, et al. Clinical investigation on pulmonary metastasis of head and neck carcinomas. Oncology. 2000 Sep;59(3):196203. [PubMed]

7. Probert JC, Thompson RW, Bagshaw MA. Patterns of Spread of Distant Metastasis in Head and Neck Cancer. Cancer. 1974 Jan;33(1):127-133. [PubMed]

8. Thomas M, Bhatt V, James G, Ayshford C. Metastasis to the thyroid from oral squamous cell carcinoma. $\mathrm{Br}$ J Oral Maxillofac Surg. 2009 Sep;47(6):500-1. [PubMed]

9. Mandai $\mathrm{T}$, Ishida $\mathrm{K}$, Ito $\mathrm{S}$, Deguchi H, Hata T, Irei I, et al. A case of spindle cell carcinoma of the tongue metastasized to the thyroid gland. Asian J Oral Maxillofac Surg. 2011 Nov;23(4):181-185. [Crossref]

10. Hegerova L, Griebeler ML, Reynolds JP, Henry MR, Gharib H. Metastasis to the thyroid gland: report of a large series from the Mayo Clinic. Am J Clin Oncol. 2015 Aug;38(4):338-42. [PubMed]

11. Shield KD, Ferlay J, Jemal A, Sankaranarayanan R, Chaturvedi AK, Bray F, et al. The global incidence of lip, oral cavity, and pharyngeal cancers by subsite in 2012. CA Cancer J Clin. 2017;67(1):51-64. [PubMed]

12. Attar E, Dey S, Hablas A, Seifeldin IA, Ramadan M, Rozek LS, et al. Head and neck cancer in a developing country: a population-based perspective across 8 years. Oral Oncol. 2010 Aug;46(8):591-6. [PubMed]

13. Ng JH, Iyer NG, Tan MH, Edgren G. Changing epidemiology of oral squamous cell carcinoma of the tongue: A global study. Head Neck. 2017 Feb;39(2):297-304. [PubMed]

14. McDowell L, Collins M, Kleid S, Rischin D, Corry J. T4 squamous cell carcinoma of the tongue without mandibular involvement: surgery or chemoradiotherapy? Oral Surg Oral Med Oral Pathol Oral Radiol. 2014 Feb; 117(2):163-9. [PubMed]
15. Stenson KM, Kunnavakkam R, Cohen EE, Portugal LD, Blair E, Haraf DJ, et al. Chemoradiation for patients with advanced oral cavity cancer. Laryngoscope. 2010 Jan;120(1):93-99. [PubMed]

16. Jones AS, Rafferty M, Fenton JE, Jones TM, Husband DJ. Treatment of squamous cell carcinoma of the tongue base: irradiation, surgery, or palliation? Ann Otol Rhinol Laryngol. 2007 Feb;116(2):92-9. [PubMed]

17. Huang Y, Wu LL, Xiang RL, Yu GY. Efficacy and Safety of Intro-Arterial Chemotherapy Combined with Radiotherapy on Head and Neck Cancer: A Systematic Review and Meta-Analysis. J Cancer 2019; 10(25):6233-6243. [PubMed]

18. Homma A, Onimaru R, Matsuura K, Thomas Robbins KT, Fujii M. Intra-arterial chemoradiotherapy for head and neck cancer. Jpn J Clin Oncol. 2016 Jan;46(1):4-12. [PubMed]

19. Kobayashi W, Kukobota K, Ito R, Sakaki H, Nakagawa H, Teh BG. Can Superselective Intra-Arterial Chemoradiotherapy Replace Surgery Followed by Radiation for Advanced Cancer of the Tongue and Floor of the Mouth? J Oral Maxillofac Surg. 2016 Jun; 74(6):1248-54. [PubMed]

20. Mitsudo K, Hayashi Y, Minamiyama S, Ohashi N, Iida M, Iwai $\mathrm{T}$, et al. Chemoradiotherapy using retrograde superselective intra-arterial infusion for tongue cancer: Analysis of therapeutic results in 118 cases. Oral Oncol. 2018 Apr;79:71-77. [Pubmed]

Please cite this article as: Tosheva G, Siderova M, Encheva E, Malinova D. Thyroid metastasis of a squamous cell carcinoma of the tongue - a rare case report. J of IMAB. 2021 Jan-Mar;27(1):3564-3567. DOI: https://doi.org/10.5272/jimab.2021271.3564

Received: 02/01/2020; Published online: 28/01/2021

Address for correspondence:

Gergana Tosheva Marinova, MD,

Clinic of Endocrinology, University Hospital "St. Marina" Varna,

1, Hr. Smirnenski Blvd., 9010 Varna, Bulgaria

E-mail: gergana_tosheva@abv.bg 